\title{
PENGGUNAAN MODUL KOMUNIKASI KELUARGA DALAM UPAYA PEMANFAATAN LAYANAN KESEHATAN: HIV/AIDS OLEH REMAJA DI WILAYAH PUSKESMAS KERAMBITAN
}

\section{Use of Family Communication Module in The Effort to Use Health Services: HIV/AIDS by Youth in The Kerambitan Health Center Area}

\author{
NLP Yunianti Suntari C ${ }^{1}$, Dewa Ayu Ketut Surinati \\ ${ }^{1}$ Jurusan Keperawatan, Politeknik Kesehatan Denpasar, Indonesia \\ 2 Jurusan Keperawatan, Politeknik Kesehatan Denpasar, Indonesia \\ Korespondensi: NLP Yunianti Suntari C dan yuni.suntari@yahoo.com
}

\begin{abstract}
ABSTRAK
Latar Belakang: Bahaya kesehatan yang paling mengancam remaja adalah kasus HIV/AIDS. Dari tahun ke tahun kasus HIV/AIDS pada remaja semakin banyak saja. Layanan kesehatan remaja di beberapa puskesmas, juga sudah disiapkan, untuk mendampingi remaja dalam menghadapi permasalahannya. Hanya saja pemanfaatannya belum optimal. Tujuan Penelitian: Tujuan penelitian ini adalah untuk mengetahui efektifitas penggunaan modul komunikasi keluarga dalam upaya pemanfaatan layanan kesehatan: HIV/AIDS oleh remaja di wilayah Puskesmas Kerambitan. Metedologi: Penelitian ini merupakan riset operasional dengan menggunakan desain kuantitatif. Riset operasional adalah proses penerapan metode analisis untuk menyelesaikan suatu masalah operasional, dengan mengidentifikasi penyebab keberhasilan dan kegagalan kegiatan melalui pendekatan operasional. Hasil: Persamaan regresi linear sederhana adalah $\mathrm{Y}=\mathrm{a}+\mathrm{bX}$. Berpedoman pada output table coefficient didapat, $\mathrm{a}=41,680$. Angka ini merupakan angka konstan yang mempunyai arti bahwa jika tidak ada modul komunikasi keluarga (X), maka nilai konsisten sikap pada layanan (Y) adalah sebesar 41,680. $\mathrm{b}=$ angka koefisien regresi. Nilainya sebesar 0,556. Angka ini mengandung arti bahwa setiap penambahan $1 \%$ pemanfaatan modul komunikasi keluarga (X), maka sikap pada layanan (Y) akan meningkat sebesar 0,556. Nilai koefisien regresi bernilai positif, memberi makna, pemanfaatan modul komunikasi keluarga berpengaruh positif terhadap sikap pada layanan puskesmas. Persamaan regresinya adalah $\mathrm{Y}=41,680+$ 0,556 X. Kesimpulan: Merujuk pada pembahasan di atas, maka dapat kita simpulkan bahwa pemanfaatan modul komunikasi keluarga berpengaruh positif terhadap sikap pada layanan HIV/AIDS oleh puskesmas.
\end{abstract}

Kata kunci: Modul komunikasi keluarga; sikap pada layanan puskesmas.

\section{ABSTRACT}

Background: The health hazard that most threatens adolescents is the case of HIVIAIDS. From year to year cases of HIVIAIDS in adolescents are increasing. Adolescent health services in several puskesmas have also been prepared to assist adolescents in dealing with their problems. It's just that its utilization is not optimal. Objectives: The purpose of this study was to determine the effectiveness of the use of the family communication module in the use of health services: HIV/AIDS by adolescents in the Kerambitan Health Center area. Methodology: This research is an operational research using a quantitative design. Operational research is the process of applying 
analytical methods to solve an operational problem, by identifying the causes of success and failure of activities through an operational approach. Result: The simple linear regression equation is $Y=a+b X$. Based on the output table coefficient obtained, $a=$ 41,680. This number is a constant number which means that if there is no family communication module $(X)$, then the consistent value of attitude towards service $(Y)$ is 41,680. $b=$ number of regression coefficients. The value is 0.556. This figure means that for every $1 \%$ addition to the use of the family communication module $(X)$, the attitude towards service (Y) will increase by 0.556. The value of the regression coefficient is positive, giving meaning, the use of the family communication module has a positive effect on attitudes to health center services. The regression equation is $Y=$ $41,680+0,556$ X. Conclusion: Referring to the discussion above, we can conclude that the use of the family communication module has a positive effect on attitudes towards HIV/AIDS services by the puskesmas.

Keywords: Family communication module; attitudes towards health care services.

\section{PENDAHULUAN}

tersendiri

$$
\text { Remaja }
$$

memiliki

catatan dalam masa

perkembangannya. Seperti dipahami masa remaja adalah masa pencarian jati diri. Masa mereka menemukan identitas dirinya. Pada masa ini, remaja sangat besar dipengaruhi oleh lingkungan. Pengaruh era globalisasi sangat besar memberikan pengaruh. Internet, media sosial sangat memborbardir remaja. Tidak saja mempengaruhi dalam hal informasi, bahkan juga gaya hidup, termasuk perilaku kesehatan. HIV/AIDS adalah salah satu dampak dari perubahan perilaku kesehatan. Angka kejadian semakin tahun, semakin meningkat. Bahkan angka kejadian pada remaja cukup tinggi. Sesuatu yang masih bisa diupayakan dengan tindakan pencegahan. Pengaruh yang kuat ini, remaja perlu melengkapi dirinya dengan filter. Keluarga sebagai tempat bertumbuhnya remaja, adalah filter bagi remaja, berupa pendidikan yang diberikan keluarga. Persoalannya, keluarga masa kini adalah keluarga yang sibuk dengan beragam aktifitas. Kemudian banyak keluarga berdalih tidak adanya panduan apa yang seharusnya dilakukan untuk remaja. Karena pada masa lalu, anak akan tumbuh dengan sendirinya sesuai dengan perkembangannya.

Remaja berada dalam masa transisi/peralihan dari masa kanak-kanak untuk menjadi dewasa. Secara fisik, remaja dapat dikatakan sudah matang tetapi secara psikis/kejiwaan belum matang. Beberapa sifat remaja yang menyebabkan tingginya resiko antara lain: rasa keingintahuan yang besar tetapi kurang mempertimbangkan akibat dan suka mencoba hal-hal baru untuk mencari jati diri.

Bila tidak diberikan informasi/pelayanan remaja yang tepat dan benar, maka perilaku remaja sering mengarah kepada perilaku yang beresiko, seperti: penyalahgunaan NAPZA (Narkotika, Psikotropika dan Zat Adiktif lainnya), perilaku yang menyebabkan mudah terkena infeksi HIV/AIDS, Infeksi menular seksual (IMS), masalah gizi (anemia/kurang darah, kurang energi kronik (KEK), obesitas/kegemukan) dan perilaku seksual yang tidak sesuai dengan normanorma yang berlaku. Karenanya remaja perlu mendapat bimbingan, arahan dalam menjalani masa remajanya. Menjadi tugas orang dewasa untuk membantu remaja. 
Tugas ini, menjadi perhatian pemerintah, dalam hal ini Kementerian Kesehatan. Negara memiliki kewajiban memenuhi dan melindungi remaja dari penyakit dan risiko seksual serta reproduksi, termasuk di dalamnya HIV\&AIDS. Mewujudkan kewajiban ini, maka di beberapa Puskesmas disiapkan layanan PKPR (Pelayanan Kesehatan Peduli Remaja). Beberapa layanan lain yang disiapkan di PKPR ini, pemeriksaan kehamilan bagi remaja, konseling semua masalah kesehatan reproduksi dan seksual, konsultasi mengenai masalah kejiwaan, HIV\&AIDS, Infeksi Menular seksual, Anemia.

$$
\text { PKPR adalah Pelayanan }
$$

Kesehatan yang ditujukan dan dapat dijangkau oleh remaja, menyenangkan, menerima remaja dengan tangan terbuka, menghargai remaja, menjaga kerahasiaan,peka akan kebutuhan terkait dengan kesehatannya serta efektif dan efisien dalam memenuhi kebutuhan remaja.

Bagaimana remaja dapat mengakses layanan ini? Seyogyanya remaja datang ke puskesmas untuk mendapat layanan ini. Pada kenyataannya, petugas puskesmas mendatangi remaja di kelompok khusus, seperti sekolah untuk mendekatkan layanan ini pada remaja. Masih rendahnya keinginan dan kesadaran remaja untuk datang langsung memanfaatkan layanan PKPR.

Upaya pemeliharaan kesehatan remaja untuk mempersiapkan menjadi orang dewasa yang sehat dan produktif baik sosial maupun ekonomi termasuk untuk reproduksi remaja dilakukan agar terbebas dari berbagai gangguan kesehatan yang dapat menghambat perkembangan dan kemampuan menjalani kehidupan reproduksi secara sehat.

Perkembangan remaja, meliputi:
1. Perkembangan fisik

Pertumbuhan fisik remaja mempunyai 3 ciri khas: (1) Adanya dorongan tumbuh yang kuat. (2) Adanya pertumbuhan dan perkembangan kelenjar hormon seks. (3) Meningkatnya fungsi berbagai organ tubuh sehingga menghasilkan kekuatan fisik yang besar.

2. Perkembangan psikososial kejiwaan )

Meliputi perkembangan psikososial remaja awal, pertengahan dan akhir. Cemas terhadap penampilan badan atau fisik. Perubahan hormonal. Menyatakan kebebasan dan merasa seorang individu, tidak hanya sebagai seorang anggota keluarga. Perilaku memberontak dan melawan. Kawan menjadi lebih penting. Perasaan memiliki teman sebaya. Belajar berfikir secara independen dan membuat keputusan sendiri. Terus menerus bereksperimen untuk mendapatkan citra diri yang dirasakan nyaman. Mulai membutuhkan lebih banyak teman. Mulai membina hubungan dengan lawan jenis. Senang berpetualang dan ingin bepergian secara mandiri. Harus belajar untuk mencapai kemandirian dalam bidang finansial dan emosional. Hampir siap untuk menjadi orang dewasa yang mandiri

Pada masa transisi seperti ini, remaja sangat membutuhkan bimbingan, terutama diberikan oleh orang tua. Tahap ini keluarga memiliki tugas perkembangan (1) Memberikan kebabasan yang seimbang dengan tanggung jawab mengingat remaja yang sudah bertambah dewasa dan meningkat otonominya. (2) Mempertahankan hubungan yang intim dalam keluarga. (3) Mempertahankan komunikasi terbuka antara anak dan orang tua. Hindari perdebatan kecurigaan dan 
permusuhan. (4) Perubahan system peran dan peraturan untuk tumbuh kembang keluarga.

Menjalin komunikasi yang baik antara orang tua dan remaja, adalah hal yang menantang dalam hubungan orang tua-anak. Penggunaan media menjadi suatu hal penting yang dapat membantu. Media yang digunakan dalam riset ini adalah buku panduan komunikasi antara keluarga/orang tua dan anak di rumah. Model pengasuhan keluarga, mengedepankan komunikasi dan kebersamaan. Disiapkan buku panduan yang menuntun keluarga melaksanakan pengasuhan ini. Dalam memanfaatkan buku panduan ini, di awal keluarga mendapat pendampingan. Isi buku ini adalah panduan bagi orang tua dan anak/remaja. Buku ini bertajuk "Modul Komunikasi Keluarga." Pada penelitian peneliti sebelumnya, (Suntari 2016) penggunaan media ini menunjukkan perbedaan yang bermakna, antara kelompok yang menggunakan media ini dan yang tidak, pada komponen kecerdasan emosi, dengan $p=0,000$, dan pada kemandirian remaja, dengan $\mathrm{p}=$ 0,000 .

Buku atau modul ini, peneliti susun berisikan apa yang harus dilakukan remaja dalam upaya menjadi anak yang baik. Menjadi anak yang baik adalah sebuah perjuangan. Pada proses menjadi anak yang baik, penting bagi remaja untuk memperlakukan anggota keluarga, guru, dan orang di sekitarnya dengan baik dan hormat. Menjadi anak yang baik tidak berarti menjadi sempurna, tetapi harus selalu menunjukkan sayang dan pengertian kepada orang lain.

Memuat juga, bagaimana menjadi orang tua yang baik, dengan pengasuhan efektif terhadap anak. Meliputi: (1) Dinamis : Orang tua harus mampu menyesuaikan diri dengan perubahan jaman dan mampu mengubah cara-cara berinteraksi dengan anak pada saat yang tepat. (2) Sesuai kebutuhan dan kemampuan anak : Pada usia balita orang tua menerapkan pola asuh yang tuntutan dan batasan yang tinggi dalam rangka membentuk kebiasaan positif pada anak. Ketika anak sudah lebih besar orang tua dapat melonggarkan batasan karena anak sudah mampu melakukannya sendiri. (3) Ayah dan Ibu Konsisten : Ayah Ibu harus memiliki kesamaan dalam penerapan nilai-nilai, contoh : jika ibu mengajarkan sikap hemat, ayah juga melatih anak hemat dan tidak memberi anak uang di luar pengetahuan ibu. (4) Menjadi teladan positif : Orang tua harus menjadi contoh tingkah laku yang ingin dibentuk. (5) Komunikasi yang baik : Orang tua membangun komunikasi yang baik dengan anak. Ciptakan suasana nyaman ketika berkomunikasi agar anak berani mengungkapkan perasaan dan permasalahan yang sedang dihadapinya. (6) Memberikan Pujian : Berikan pujian atau penghargaan kepada anak ketika mereka melakukan suatu hal yang baik. (7) Mempunyai pemikiran ke depan : Membiasakan untuk membuat aturan bersama dengan anak. Contoh : waktu tidur malam adalah jam 21.00

Aplikatif dari hasil penelitian terdahulu, dimanfaatkan untuk melihat hubungannya dengan sikap ramaja dalam pemanfaatan layanan PKPR oleh remaja. Peran keluarga, dalam membangun komunikasi dengan remaja, memunculkan kesadaran remaja, untuk melindungi kesehatannya dengan memanfaatkan layanan, menggunakan layanan untuk keselamatan dirinya pun teman sebayanya.

\section{TUJUAN PENELITIAN}

Tujuan penelitian ini adalah untuk mengetahui efektifitas penggunaan modul komunikasi keluarga dalam upaya pemanfaatan layanan kesehatan: 
NLP Yunianti Suntari C \& Dewa Ayu Ketut Surinati: Penggunaan Modul Komunikasi Keluarga dalam Upaya Pemanfaatan Layanan Kesehatan: HIV/AIDS Oleh Remaja di Wilayah Puskesmas Kerambitan

HIV/AIDS oleh remaja di wilayah Puskesmas Kerambitan.

\section{METODE PENELITIAN}

Penelitian ini merupakan riset operasional dengan menggunakan desain kuantitatif. Riset operasional adalah proses penerapan metode analisis untuk menyelesaikan suatu masalah operasional, dengan mengidentifikasi penyebab keberhasilan dan kegagalan kegiatan melalui pendekatan operasional. Penelitian ini dilakukan dengan beberapa tahapan yaitu :

Tahap I : Identifikasi masalah

Tahap II : Informasi Modul Komunikasi Keluarga

Tahap III : Observasi penggunaan Modul Komunikasi Keluarga

Tahap IV: Evaluasi dampak penggunaan Modul Komunikasi Keluarga, pada sikap remaja pada pemanfaatan layanan klinik remaja.

Penelitian ini menggunakan desain/rancangan studi korelasional. Melihat korelasi antara pemanfaatan model komunikasi keluarga dengan sikap remaja pada pemanfaatan layanan remaja, seperti layanan kesehatan HIV AIDS.

Mengukur besarnya pengaruh satu variabel penggunaan modul komunikasi keluarga terhadap variabel sikap remaja dalam pemanfaatan layanan kesehatan HIV/AIDS, dilanjutkan dengan uji analisis regresi linier sederhana. Model pendekatan terhadap subyek penelitian dilakukan dengan cross sectional.

\section{HASIL PENELITIAN}

modul.

Berikut disajikan pemanfaatan

Tabel 1.

Hari Pemanfaatan Modul

\begin{tabular}{ccc}
\hline $\begin{array}{c}\text { Hari } \\
\text { Menggunakan } \\
\text { Modul }\end{array}$ & Frekuensi & Persentase \\
\hline $1-5$ & 3 & 2.65 \\
\hline $6-10$ & 13 & 11.5 \\
\hline $11-15$ & 2 & 1.77 \\
\hline $16-20$ & 50 & 44.25 \\
\hline $21-25$ & 11 & 9.73 \\
\hline $26-30$ & 34 & 30.1 \\
\hline Jumlah & $\mathbf{1 1 3}$ & $\mathbf{1 0 0}$ \\
\hline
\end{tabular}

Sikap remaja dalam memanfaatkan tempat rujukan layanan remaja.

Tabel 2.

Sikap pada Layanan

\begin{tabular}{ccc}
\hline $\begin{array}{c}\text { Sikap } \\
\text { pemanfaatan } \\
\text { layanan }\end{array}$ & Frekuensi & Persentase \\
\hline $31-35$ & 1 & 0.89 \\
\hline $36-40$ & 4 & 3.54 \\
\hline $41-45$ & 12 & 10.62 \\
\hline $46-50$ & 20 & 17.71 \\
\hline $51-55$ & 14 & 12.39 \\
\hline $56-60$ & 25 & 22.12 \\
\hline $61-65$ & 18 & 15.93 \\
\hline $66-70$ & 13 & 11.5 \\
\hline $71-75$ & 3 & 2.65 \\
\hline $76-80$ & 3 & 2.65 \\
\hline Jumlah & $\mathbf{1 1 3}$ & $\mathbf{1 0 0}$ \\
\hline
\end{tabular}

Uji korelasi penggunaan modul komunikasi keluarga oleh keluarga dan remaja dengan sikap remaja dalam memanfaatkan tempat rujukan layanan remaja 
NLP Yunianti Suntari C \& Dewa Ayu Ketut Surinati: Penggunaan Modul Komunikasi Keluarga dalam Upaya Pemanfaatan Layanan Kesehatan: HIV/AIDS Oleh Remaja di Wilayah Puskesmas Kerambitan

Tabel 3.

Uji Korelasi Pearson

\begin{tabular}{|c|c|c|c|}
\hline & & $\begin{array}{l}\text { Modul } \\
\text { Komunikasi }\end{array}$ & $\begin{array}{l}\text { Sikap } \\
\text { pada } \\
\text { Layanan }\end{array}$ \\
\hline \multirow{4}{*}{$\begin{array}{l}\text { Modul } \\
\text { Komuni- } \\
\text { kasi }\end{array}$} & Pearson & 1 & $.419^{* *}$ \\
\hline & $\begin{array}{l}\text { Corre- } \\
\text { lation }\end{array}$ & & \\
\hline & $\begin{array}{l}\text { Sig. (2- } \\
\text { tailed) }\end{array}$ & & .000 \\
\hline & $\mathrm{N}$ & 113 & 113 \\
\hline \multirow{3}{*}{$\begin{array}{l}\text { Sikap } \\
\text { pada } \\
\text { Laya- } \\
\text { nan }\end{array}$} & $\begin{array}{l}\text { Pearson } \\
\text { Correla } \\
\text {-tion }\end{array}$ & $.419^{* *}$ & 1 \\
\hline & $\begin{array}{l}\text { Sig. } \\
\text { tailed) }\end{array}$ & .000 & \\
\hline & $\mathrm{N}$ & 113 & 113 \\
\hline
\end{tabular}

**. Correlation is significant at the 0.01 level (2tailed).

Pada tahap berikutnya dilakukan uji normalitas data. Uji ini diperlukan untuk melihat kondisi data yang ada, menjelang dilakukan analisa korelasi variabel. Semua analisa pada penelitian ini menggunakan program IBM SPSS Statistic 23.

Tabel 4.

Uji Normalitas Data dengan One-Sample Kolmogorov-Smirnov Test

\begin{tabular}{llr}
\hline \multicolumn{3}{c}{ Unstandardized Residual } \\
\hline $\mathrm{N}$ & & 113 \\
\hline \multirow{2}{*}{$\begin{array}{l}\text { Normal } \\
\text { Parameters }\end{array}$} & Mean & .0000000 \\
\cline { 2 - 3 } & $\begin{array}{l}\text { Std. } \\
\text { Deviation }\end{array}$ & 8.80879613 \\
\hline \multirow{2}{*}{$\begin{array}{l}\text { Most Extreme } \\
\text { Differences }\end{array}$} & Absolute & .070 \\
\cline { 2 - 3 } & Positive & .070 \\
\cline { 2 - 3 } $\begin{array}{l}\text { Kolmogorov-Smirnov Z } \\
\text { Asymp. Sig. (2-tailed) }\end{array}$ &. .041 \\
\hline a. Test distribution is Normal. \\
b. Calculated from data.
\end{tabular}

Mengetahui kedua variabel mempunyai hubungan yang linear. Jika nilai signifikansi lebih besar dari 0,05 , maka kesimpulannya adalah terdapat hubungan linear secara signifikan antara kedua variabel.
Tabel 5.

Linieritas: ANOVA Table

\begin{tabular}{|c|c|c|c|c|c|c|}
\hline \multicolumn{4}{|c|}{ Sum of Squares } & df & M. & Sig. \\
\hline \multirow{6}{*}{$\begin{array}{l}\text { Modul } \\
\text { Komu- } \\
\text { nikasi * } \\
\text { Sikap } \\
\text { pada } \\
\text { Layanan }\end{array}$} & \multirow{3}{*}{$\begin{array}{l}\text { Bet } \\
\text { wee } \\
n \\
\text { Grou } \\
\text { ps }\end{array}$} & $\begin{array}{l}\text { (Com- } \\
\text { bined) }\end{array}$ & $\begin{array}{r}3371 \\
.548 \\
\end{array}$ & 37 & 91.123 & 2.631 \\
\hline & & Lin.. & $\begin{array}{r}1046 \\
307\end{array}$ & 1 & 1046.3 & 30.20 \\
\hline & & $\begin{array}{l}\text { Dev } \\
\text { from } \\
\text { Lin.. }\end{array}$ & $\begin{array}{r}2325 \\
.242\end{array}$ & 36 & 64.590 & 1.865 \\
\hline & \multirow{2}{*}{\multicolumn{2}{|c|}{$\begin{array}{l}\text { Within } \\
\text { Groups }\end{array}$}} & 2597 & 75 & 34.639 & \\
\hline & & & .956 & & & \\
\hline & \multicolumn{2}{|c|}{ Total } & $\begin{array}{r}5969 \\
.504\end{array}$ & $\begin{array}{r}11 \\
2\end{array}$ & & \\
\hline
\end{tabular}

Tabel 6.

Uji Heterokedastisitas

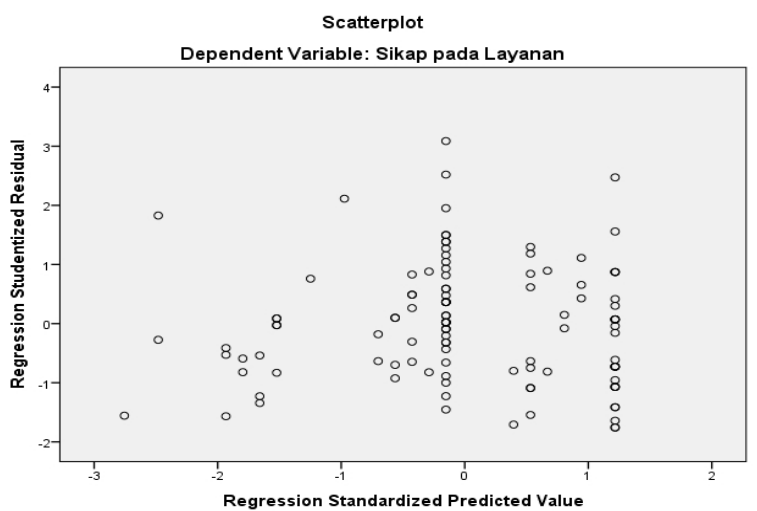

Tabel 7.

Uji Analisis Regresi Linier Sederhana; Coefficients $^{\mathrm{a}}$

\begin{tabular}{|c|c|c|c|c|c|c|}
\hline \multirow{2}{*}{\multicolumn{2}{|c|}{ Model }} & \multicolumn{2}{|c|}{$\begin{array}{l}\text { Unstandardi } \\
\text { zed } \\
\text { Coefficients }\end{array}$} & $\begin{array}{l}\text { Standardized } \\
\text { Coefficients }\end{array}$ & \multirow[t]{2}{*}{$\mathrm{t}$} & \multirow[t]{2}{*}{ Sig. } \\
\hline & & $\mathrm{B}$ & $\begin{array}{l}\text { Std. } \\
\text { Error }\end{array}$ & Beta & & \\
\hline \multirow{4}{*}{1} & (Constant) & $\begin{array}{l}41 \\
.6\end{array}$ & 2.557 & & $\begin{array}{l}16 . \\
298\end{array}$ & $\begin{array}{l}.00 \\
0\end{array}$ \\
\hline & & 80 & & & & \\
\hline & Modul & .5 & .115 & .419 & 4.8 & .00 \\
\hline & Komunikasi & 56 & & & 57 & 0 \\
\hline
\end{tabular}

a. Dependent Variable: Sikap pada Layanan

Tabel 8.

Model Summary ${ }^{\mathrm{b}}$

\begin{tabular}{cc}
\hline R Square & Adjusted R Square \\
\hline .175 & .168 \\
\hline
\end{tabular}

a. Predictors: (Constant), Modul Komunikasi

b. Dependent Variable: Sikap pada Layanan 


\section{PEMBAHASAN}

Pengaruh besar era global ini membuat remaja bergerak dalam kebebasan. Apalagi ketika keluarga, orang tua, tidak mampu mengikuti dengan cepat perubahan yang terjadi. Kondisi yang menjauhkan remaja dari keluarganya, dan mendekatkan mereka pada budaya pluralism dengan arah yang bebas. Peran aktif orang tua sangat diutamakan. Karena di dalam keluarga anak akan memperoleh pendidikan dasar sebagai landasan pembentuk karakter yang baik sebagia bekalnya menuju dunia dewasa, tempat bertumbuh dan berinteraksi dengan lingkungan.

Keluarga menjadi penyelesai masalah, ada delapan model intervensi yang bisa dikembangkan (Hook, 2008) dalam mengatasi antara lain: 1) social learning approach to family counseling, yang menekankan pada pembelajaran ketrampilan baru, perilaku yang ditampilkan dan memperbaharui kepercayaan; 2) structural family therapy, yang menekankan pada mengkreasikan efektifitas organisasi keluarga; 3) solution focused family therapy, yang menekankan pada mengembangkan solusi baru terhadap masalah yang dihadapi; 4) Narative family therapy, yang menekankan pada transformasi permasalahan kepada harapan yang diinginkan; 5) Psychoeducational approaches to family counseling, yang menekankan pada kemungkinan anggota keluarga mengatasi sakit atau permasalahan lainnya; 6) Multisystem approach to family therapy, menekankan pada kemungkinan keluarga yang mengalami banyak masalah dengan dihubungkan dengan system support; 7) Object relation family therapy, yang menekankan pada issue hubungan interpersonal dengan pengalaman hidupnya; 8) Spirituality, yang menekankan pada perasaan mengenai arti, nilai dan hubungan dengan aspekaspek kehidupan.

Penelitian ini menggali data tentang penggunaan atau pemanfaatan modul komunikasi keluarga oleh keluarga dan remaja. Mengidentifikasi sikap remaja dalam memanfaatkan tempat rujukan layanan remaja. Dan menemukan hubungan penggunaan modul komunikasi keluarga oleh keluarga dan remaja dengan sikap remaja dalam memanfaatkan tempat rujukan layanan remaja. Hasil pengukuran berdasarkan pengisian kuesioner oleh responden.

Pemanfaatan modul komunikasi keluarga oleh keluarga dan remaja

Modul komunikasi ini adalah pengembangan dari model komunikasi keluarga yang peneliti susun pada penelitian terdahulu. Modul ini digunakan oleh keluarga sebagai pedoman atau panduan dalam komunikasi keluarga. Keluarga dengan anak yang beranjak remaja dipandu untuk mengadakan kegiatan bersama secara rutin setiap hari. Peneliti tidak menentukan waktu kegiatan, karena keluarga akan mengatur waktu sesuai dengan kesediaan masing-masing anggota keluarga.

Studi ini mengarahkan kegiatan setiap hari, keluarga menyiapkan waktu untuk berinetraksi bersama remaja dalam satu kegiatan bersama. Kegiatan bisa beragam. Bisa saat makan bersama, memperbaiki perabotan rumah, menyiapkan alat upacara. Dalam kebersamaan ini, mereka dikondisikan saling berkomunikasi. Kemudian masing-masing, baik orang tua maupun anak, melakukan self evaluation. Bagaimana perasaan mereka saat berinteraksi dan berkomunikasi tersebut. Segala kegiatan dipandu dalam modul komunikasi keluarga.

Modul ini berisikan catatancatatan pengingat, akan hal-hal yang 
harus dipahami keluarga. Berisikan juga panduan yang harus dilakukan keluarga, orang tua dan remaja, dalam keseharian mereka berinteraksi.

Remaja yang rentan dicermati sebagai kesadaran diri, berarti mengetahui apa yang kita rasakan pada suatu saat dan menggunakannya untuk memandu pengambilan keputusan diri sendiri, memiliki tolak ukur yang realistis atas kemampuan diri dan kepercayaan(Andriani, 2014). Lebih lanjut Ghajarzadeh, Owji, \& Sahraian (2014) menyatakan Emotional intelligence (EI) has been defined as the ability to manage and elucidate the one's own and other's emotions and feelings to apply proper information for verifying thoughts and actions.

Menyadarkan kita bahwa kecerdasan emosi sangat penting bagi setiap individu, dalam menunjang kesuksesan dan kebahagiaan mereka, dalam pekerjaan, pergaulan, dan semua aspek kehidupan. Beberapa ciri pribadi yang cerdas secara emosional perlu ditumbuhkembangkan pada setiap individu, sejak dini. Anak-anak, remaja perlu mendapat pengetahuan, bimbingan dan contoh, bagaimana menjadi pribadi yang cerdas secara emosi. Penekanan upaya menunjukkan ciri cerdas secara emosi ini dinyatakan dalam buku panduan keluarga atau "Modul Komunikasi Keluarga".

Layanan yang dibutuhkan remaja adalah layanan yang dapat membantu dan membimbing mereka menjadi individu yang memiliki kecerdasan. Ciri pribadi yang cerdas secara emosi (1) Bersikap positif. Fokus hanya pada hal-hal positif. (2) Mereka yang berpikiran positif, akan berkumpul dengan orang-orang yang berpikiran positif juga. (3) Assertif, adalah sikap tegas dalam mengemukakan pendapat tanpa menyinggung perasaan lawan bicara. (4) Visioner, yang siap melupakan kegagalan di masa lalu. (5) Mereka tahu cara membuat hidup lebih bahagia dan bermakna. (6) Mereka tahu bagaimana mengeluarkan energy dengan lebih bijak. (7) Terus belajar dan berkembang.

Keluarga merupakan lembaga yang paling penting dalam proses perkembangan anak. Pada sebuah keluarga, anak mendapatkan aturanaturan atau norma, nilai-nilai dan pendidikan yang sangat diperlukan untuk menghadapi lingkungan dimana dia tinggal. Melalui pendidikan setiap individu diharapkan dapat memahami dan mempelajari norma yang ada di masyarakat. Pengasuhan keluarga memberikan dasar pembentukan tingkah laku watak, moral, dan pendidikan anak.

Tugas perkembangan keluarga yang memiliki remaja pada intinya menyiapkan remaja memasuki babak baru dalam kehidupan mereka. Menyeimbangkan kebebasan dengan tanggung jawab seiring dengan kematangan remaja dan semakin meningkatnya otonomi. Orang tua secara progresif harus mengubah hubungan mereka dengan anak remaja mereka. Yaitu dari hubungan sebelumnya yang bergantung, menjadi hubungan memandirikan remaja.

Kedudukan dan fungsi suatu keluarga dalam kehidupan manusia bersifat primer dan fundamental. Pada hakekatnya keluarga merupakan wadah pembentukan masing-masing anggota. Terutama anak-anak yang masih dalam pengawasan dan tanggung jawab orang tua. Keluarga membantu anak dalam proses perkembangannya, yang meliputi keadaan fisik, intelektual, kecerdasan sosial, emosi, kepercayaan, dan kemandiriannya. Ketika semuanya berjalan dengan baik, anak-anak akan cerdas secara emosi, dan mampu mandiri dalam berinteraksi di lingkungan sosialnya. 
NLP Yunianti Suntari C \& Dewa Ayu Ketut Surinati: Penggunaan Modul Komunikasi Keluarga dalam Upaya Pemanfaatan Layanan Kesehatan: HIV/AIDS Oleh Remaja di Wilayah Puskesmas Kerambitan

\section{KESIMPULAN}

Keterbatasaan dalam penelitian ini ditemukan pada pemanfaatan buku panduan keluarga, saat pendampingan. Keluarga tidak dapat dengan segera memahami cara penggunaan buku, jika pendamping keluarga tidak ada. Tentu hal ini akan menjadi tantangan ketika keluarga harus mengerjakannya secara mandiri. Dalam buku panduan ini juga, akan lebih bermakna jika mencantumkan tip-tip atau saran-saran ringan untuk keluarga dan remaja, agar dapat dan mudah dilakukan sehari-hari, dalam hal meningkatkan kecerdasan emosi dan kemandirian.

\section{DAFTAR PUSTAKA}

Badan Kependudukan dan Keluarga Berencana Nasional, Badan Pusat Statistik, Kementerian Kesehatan. (2013). Indonesian Demographic and Health Survey 2012. Jakarta.

Direktorat Jendral PP dan PL, Kementerian Kesehatan RI. (2012). Situasi Perkembangan HIV AIDS di Indonesia. Jakarta.

Hurlock, B. Elizabeth. (2013). Perkembangan Anak. Jilid 1. Jakarta: Penerbit Erlangga.

Komisi Penanggulangan AIDS Nasional. (2009). Situasi HIV dan AIDS di Indonesia. Jakarta.

Mansoer, Arif, dkk. (2004). Kapita Selekta Kedokteran. Ed. 3. Jakarta: Penerbit Media Aesculapus fakultas Kedokteran Universitas Indonesia

Marubenny S. (2011). Perbedaan Respon Sosial Penderita HIVAIDS yang Mendapat Dukungan Keluarga dan Tidak Mendapat Dukungan Keluarga di Balai Kesehatan Paru (BKPM) Semarang. Thesis. Universitas Muhammadiyah Semarang.
Saifuddin, A. (2012). Reliabilitas dan Validitas, Edisi 4, Yogyakarta: Pustaka Pelajar.

Saifuddin, A. (2012). Penyusunan Skala Psikologi, Edisi 2. Yogyakarta: Pustaka Pelajar.

Setiawan HH. (2014). Pola Pengasuhan Keluarga dalam Proses Perkembangan Anak. Jurnal 
NLP Yunianti Suntari C \& Dewa Ayu Ketut Surinati: Penggunaan Modul Komunikasi Keluarga dalam Upaya Pemanfaatan Layanan Kesehatan: HIV/AIDS Oleh Remaja di Wilayah Puskesmas Kerambitan 